\title{
END-OF-LIFE DESIGN FOR COMPOSITE ROTORS
}

\author{
By: \\ J.H. Beno \\ R.C. Thompson \\ M.D. Werst \\ S.M. Manifold \\ J. Zierer
}

10th EML Symposium, April 25-28, 2000, San Francisco, CA

IEEE Transactions on Magnetics, vol. 37 no. 1, January 2001, pp. 284-289

PR - 282

Center for Electromechanics

The University of Texas at Austin

PRC, Mail Code R7000

Austin, TX 78712

(512) 471-4496

April 13, 2000 


\title{
End-of-Life Design for Composite Rotors
}

\author{
J.H. Beno, R.C. Thompson, M.D. Werst, S.M. Manifold, and J.J. Zierer \\ The University of Texas at Austin Center for Electromechanics
}

\begin{abstract}
The University of Texas Center for Electromechanics (UT-CEM) is developing flywheel energy storage systems for combat and commercial vehicles and also leads the major U.S. Flywheel Safety and Containment Program, a consortium effort of several leading flywheel developers. Safety for high performance composite flywheel systems on combat vehicles presents special challenges that impact the design of all flywheel components, especially the composite rotor and the bearings. This paper will present an overview of the issues and discuss design strategies and solutions applicable to the combat vehicle environment, using the flywheel energy storage system design recently completed under the Defense Advanced Research Projects Agency (DARPA) Combat Hybrid Power System (CHPS) Program as a case study. In particular, the paper will trace basic design and safety strategy, fatigue cycle development, lifetime design approach, and the resulting design margins.
\end{abstract}

\section{INTRODUCTION}

$\mathrm{T}$ HE University of Texas Center for Electromechanics (UT-CEM) recently completed a detail design process for a $5 \mathrm{MW}$ flywheel energy storage system for the Defense Advanced Research Projects Agency (DARPA) Combat Hybrid Power System (CHPS) Program. The process traced desired mission capabilities through design decisions, finite element model (FEM) analysis, lifetime and fatigue analysis, subcomponent testing and final design development. The design process focused on balancing risk and subcomponent life-limiting stress to develop a high performance rotor design that will fully meet the expected life of a combat vehicle with known safety margins on both stress and number of cycles of operation.

This paper presents (1) methods of applying statistical probabilities of failure to design of the composite portions of flywheel rotors and (2) lessons learned using the recent NASA FLAGRO code for metallic rotor components. This paper will conclude with discussion of how these techniques are being applied to UT-CEM compulsator rotor design and how they impact safety and containment strategies for composite flywheels on combat vehicles. The paper focuses on design, approach, analysis, and design tools used to ensure that the CHPS machine rotor would have a fatigue life consistent with an anticipated 40,000 mile life of wheeled combat

Manuscript received December 21, 1999. The work presented here was funded by SAIC under the DARPA/US Army TARDEC Combat Hybrid Power System program from June 1997 through April 1999 (Subcontract No. 4500002919). vehicles and would also provide adequate levels of safety for crew members.

The CHPS flywheel system was designed to perform mobility load leveling as a component within a combat vehicle hybrid electric drive train, as well as provide pulse power at the 3 to $8 \mathrm{MW}$ level to a pulse forming network for offensive and defensive weapons. Addressing these two roles resulted in a complex rotor structure with characteristics commonly found in many advanced "flywheel battery" designs and additional characteristics to meet the pulse power requirements. For example, the mobility load leveling mission implies a relatively continuous operation that is uncharacteristic for pulse weapon power supplies. Alternatively, envisioning operation on a combat vehicle in a silent watch mode, with weapons ready, places a premium on low idling losses that is even more stringent than for most "flywheel battery" applications. Needless to say, minimizing mass and volume were also primary design objectives. Although design trade-offs are not the topic of this paper, the unique combination of mission goals led to a high performance rotor structure (shown later in this paper) that incorporated permanent magnets for the motor-generator, laminations for magnetic bearings, back-up bearing components, metallic support sleeve, and composite bandings. Design optimization resulted in peak operational speeds for flywheel to be set at 20,000 rpm.

\section{LIFE REQUIREMENTS, FATIGUE CYCLE DEVELOPMENT, COMPOSITE SAFETY APPROACH, AND OTHER DESIGN CONSIDERATIONS}

Fatigue and safety design must be undertaken with the end application in mind, i.e., the flywheel design is linked with the mission of the host combat vehicle. The most taxing application for the CHPS flywheel would be on a wheeled combat vehicle equipped with pulse offensive and defensive weapons such as an ElectroThermal-Chemical (ETC) gun, EM Armor, and laser air defense. The following observations can be made concerning the machine's duty cycle for this demanding application over a typical 40,000 mile, 15 to 25 year life of the vehicle:

- The vast majority vehicle miles (30,000 miles) would be with weapons off for maneuver tactical training, road marches, and peace time operations. The CHPS flywheel can support these missions (mobility load leveling) operating between 11,000 and 14,000 rpm (less than $50 \%$ of the rotor stress incurred at full 20,000 rpm operation). 
- Gunnery training for the ETC weapon, with EM Armor activated (potentially a range safety requirement), while performing mobility load leveling, applies for less than 5,000 miles of operation and can be met with flywheel speeds of 14,000 to $16,000 \mathrm{rpm}$ (less than $65 \%$ of the stress incurred at full 20,000 rpm operation)

- To ensure safety of surrounding aircraft, full power laser firing will likely not be allowed during tactical maneuver training. The requirement to use the air defense laser with the flywheel also performing mobility load leveling functions will likely only occur during actual combat. There will likely be a laser check-out and maintenance requirement (perhaps monthly).

- Full combat operation, requiring the flywheel to operate between 15,000 and 20,000 rpm, will likely only occur for approximately 1000 miles.

- There is considerable uncertainty in the actual duty cycle. Consequently, designs based on the above comments require high margins of safety.

It is typical (if the duty cycle is well understood) to design for a fatigue life of two to four times the required component life requirement. (See, for example, NASA requirements for the International Space Station, requiring four times life for fracture-critical components [1].) Since there is considerable uncertainty in the actual duty requirements of a combat vehicle, a ten times (10X) fatigue life requirement was assumed for all CHPS rotor components.

Fatigue design for metallic components is reasonably well understood and existing design analysis tools exist that range from simple factor of safety approaches to more advanced fatigue analysis. One of the most advanced tools in common use is FLAGRO (developed by NASA), and was used extensively in analysis of the metallic components of the CHPS rotor (see Section IV below). Input for FLAGRO requires quantitative duty cycle information. For the CHPS application, this required development of a suitable profile for the mobility load leveling mission, with pulse power requirements superimposed. The light duty vehicle Federal Urban Driving Schedule (FUDS) was selected as the model for mobility load leveling because it was readily available so it could serve as a model for other designers and it involved more speed fluctuations than other FUDS (e.g., heavy duty vehicle version), which made it more demanding and representative of combat vehicle operations. While mobility load-leveling alone could be met by cycling the flywheel between 11,000 and 14,000 rpm, the additional power and energy requirement for EM armor results is shifting the flywheel operation speed upward to operate between 14,000 and 16,000 rpm. To illustrate this approach, Fig. 1 (which is based on simulations) shows flywheel speed (energy) fluctuations required to provide mobility load-leveling for the selected FUDS, shifted upward so that EM armor discharges and ETC firing are possible at any instant.
While safe design of highly stressed metallic components is well understood, safe design of highly stressed composite flywheel rings is an emerging science, with several ongoing developmental programs focused on composite rotor safety, containment, life cycle, and fatigue issues. It is commonly accepted and reasonable to assume that if stresses are kept sufficiently low, composite flywheels can operate in the vicinity of people without containment for potential but unanticipated burst events (for example, this "no-containment" approach has been selected by NASA for a high speed composite flywheel under development for the International Space Station). Noting that the CHPS machine will operate at greatly reduced stresses for most of its lifetime, and will operate at full stress only during combat, the following layered safety approach was developed for the CHPS machine:

- Design rotor composite rings with suitable margins for personnel safety at full 20,000 rpm operation without containment and base these design margins on accepted practices for similar materials in other highly stressed applications.

- Incorporate blast shields in the vehicle design for additional crew protection.

- When operating the vehicle in the vicinity of bystanders, operate the flywheel at reduced speed/stress (in practice, this is easily met since mobility load leveling operation can be met with the flywheel operation at a peak stress of less than $50 \%$ of the stress at the full 20,000 rpm operation).

The first item in the above list mentions "accepted practices." Since composite materials are constantly undergoing refinements and not well standardized (compared to metals), a statistical approach to avoiding catastrophic failure is most suitable. Although the details of the statistical approach are describe in more detail in the following section, Table 1 shows that many applications accept a probability of not experiencing catastrophic failure (success probability) of 0.999999 (six nines, annotated as $0.9_{6}$ ) [2]. For the CHPS application, as will be seen later, a success probability of better than $0.9_{8}$ was obtained.

\section{Technical Overview of the Design ApProach}

\section{A. Statistical Design Approach}

Military Handbook 17 guided the design of the composite portions of the CHPS rotor. As specified in this document, composite design and testing procedures are statistically based and tailored for specific applications. For the CHPS rotor, a process was developed that built on previous UT-CEM experience and is suitable for prototypes and other small quantity applications. The goal was to establish a process in which sample testing can be part of the fabrication/production process, qualifying each rotor individually. An alternative approach would entail standardizing manufacturing processes and vendors and conducting lot-to-lot sampling - too expensive for the current application. To qualify individual rotors requires 
that each rotor be constructed from one lot of raw material and that statistical based qualification testing be conducted as part of the fabrication process, using the same material lot for the rotor rings and the test samples. Furthermore, cost is greatly reduced if statistical processes are used that are compatible with small sample sizes.

The fact that many material properties, particularly for composites, can be reasonably well represented by the Gaussian (also referred to as Normal) Distribution function, greatly simplifies the process because it is known that the Student's " $t$ " Distribution function is a distribution function that captures small sample statistics [3] and closely approximates the Normal Distribution function for larger samples (the differences are extremely minor for sample sizes greater than 50 and the two functions are mathematically equivalent in the limit of large sample sizes) [4]. Statistical sampling requires a measurable material property and, for CHPS, strain-to-failure for composite rings was selected as for this measurable property because (1) UT-CEM had previously developed techniques and test fixtures to measure this property, (2) UT-CEM had previously experienced good success in relating strain-to-failure measurements with predicted burst speeds on the UT-CEM Transit Bus Flywheel program, and (3) strain to failure data collected by UTCEM is well represented by the normal distribution, a fact that has been verified by statistical tests and by plotting this data on probability graph paper (which plots relative cumulative frequency vs. strain-to failure) to verify a good fit with a straight line (linear correlation coefficient exceeds 0.99).

Fig. 2 illustrates the statistical qualification approach. The process involves the following steps:

- Fabricate rotor rings and five to thirty test rings (to be described shortly), using the same material lot and identical processing steps for all rings.

- Conduct strain-to-failure tests to calculate mean strain-to-failure and the probability distribution curve.

- Select a maximum operating strain for the final CHPS rotor such that the area under the right hand portion of the curve (shaded region in Fig. 2) comprises at least $99.9999 \%$ of the total area under the curve. This maximum operating strain establishes the flywheel peak operating speed.

By this process, the final CHPS operating speed would not be fully established until the rotor composite rings and test samples were fabricated and test results were analyzed; however, based on typical strain-to-failure results in previous programs, it appeared that the CHPS composite rings would be able to operate at the design speed of 20,000 rpm with at least $9_{8}$ under the probability of "not-bursting" curve. As will be described in the next paragraph, this assumes that collecting future statistical samples of 10 tests will result in means and standard deviations similar to those determined with our previous samples of six to eight.

As mentioned previously, the Student's “t” Distribution is applicable for small sample sizes.
Increasing the number of test samples (assuming the standard deviation remains relatively constant) has the effect of reducing the area under the tails of the distribution and causing the central peak to grow so that more of the distribution is bunched near the mean. This essentially means that if a given maximum operating strain is desired, it is frequently possible to also obtain a desired probability of not bursting by increasing the number of test samples. The impact of this phenomenon is depicted in Fig. 3 for the CHPS composite bandings. For this figure, previous strain-to-failure data for the composite system selected for the CHPS rotor was used and this curve would likely be modified slightly after fabrication and testing of the test samples that accompany the CHPS rotor ring fabrication. This curve indicates that fabrication and successful testing of 10 to 12 test samples would be sufficient to fully achieve the safety objectives for the CHPS rotor.

\section{B. Fatigue Analysis Approach}

Two fatigue analysis methodologies have been pursued for the metallic components of the CHPS rotor. Initially, classical fatigue diagrams or "modified Goodman" diagrams that utilize S-N data for specific load ratios were used. A realistic duty cycle was constructed, as described in section III, and fatigue modifying factors were applied. Fatigue modifying factors provide a method of accounting for stress concentrations, surface finish, reliability, size and temperature effects.

The second fatigue analysis method consists of a fracture mechanics approach to component safe-life. Although this method is only a few decades old, it is mature enough to have become widely accepted by both government and industry. A NASA-developed code, FLAGRO [5] was used for calculating safe-life for CHPS rotor components with assumed initial flaws and realistic duty cycles. The initial flaws are assumed to be in the worst possible location and orientation (highest stress region and direction) and to be as large as practically detectable by standard nondestructive testing techniques.

Early in the CHPS rotor development effort, the FLAGRO software was used to compare several candidate materials for the back iron structure of the permanent magnet (PM) motor/generator. Although numerous ferromagnetic steel alloys were evaluated, two more promising candidates were AerMet ${ }^{\circledR} 100$ and 4340 . Simple S-N data, provided by Carpenter [6] , make high strength steels like Aermet ${ }^{\circledR} 100$ appear very attractive as a candidate material for the CHPS rotor back-iron as shown in Fig. 4.

The data shown are for polished fatigue specimens. However, similar curves for notched AerMet ${ }^{\circledR} 100$ specimens show a rapid decrease in fatigue strength as the stress concentrations are increased in severity. AerMet ${ }^{\circledR}$ 100 notch sensitivity becomes apparent when one examines the $\mathrm{dA} / \mathrm{dN}$ vs. stress intensity for AerMet ${ }^{\circledR} 100$ compared to mildly heat-treated AISI 4340 alloy as shown in Fig. 5. Crack propagation data for the AerMet ${ }^{\circledR} 100$ material was acquired from a study performed by the 
Navy, which was evaluating AerMet ${ }^{\circledR} 100$ for aircraft landing gear applications [7]. The rest of the materials and heat-treatment variations pre-existed in the FLAGRO material database.

Stress intensity (shown as $\Delta \mathrm{K}$ in Fig. 5) is a function of the stress excursion, geometry and stress field at the crack tip. This curve shows that a for the same loading, a small crack or flaw in AerMet ${ }^{\circledR} 100$ will propagate at a higher rate than in the 4340 steel.

Results indicate that mildly heat-treated AISI 4340 steel is superior in fatigue for the given loading conditions. Although the 4340 does not have as high a yield strength as the other alloys evaluated, it satisfied the required factors of safety and gives the highest margin on safe-life rating for the CHPS rotor.

\section{Resulting Design of THE CHPS Rotor}

\section{A. Rotor Design Overview}

A full cross-section of the CHPS rotor is illustrated and the rotating components are identified in Fig. 6.

The CHPS rotor is safe-life rated for the specified duty cycle, which include speeds up to 20,000 rpm and operating temperature excursions from $0^{\circ} \mathrm{F}$ to $225^{\circ} \mathrm{F}$. The CHPS rotor has a preloaded, multi-ring composite flywheel structure, which supports the internal, full-length back iron. The major enhancement of this current design, over earlier design iterations, is the full-length back iron to reduce induced shear stresses in the composite flywheel structure. The flywheel rings are filament wound using IM7 carbon fiber towpreg with a Hexcel toughened epoxy and then autoclave cured.

Radially inboard of the back iron, in the central section of the rotor, is the PM cartridge. This PM cartridge is the rotating portion of the PM motor/generator. The PM cartridge consists of PM segments preloaded inside the back iron, axially constrained by retainers, and radially constrained by an internal composite bore liner. During component development activities, a full-scale mockup of the PM cartridge was tested in a spin pit. The design exhibited excellent mass balance stability through full duty cycle and thermal excursions during the tests.

A need for low idling losses during silent watch missions led to selection of magnetic bearings. Magnetic bearings also allow for spin growth of the rotor with respect to the stationary magnetic actuators, eliminating the need for arbors. Shown in the rotor cross-section are the radial and combination (radial and thrust) bearing components. These components consist of 4130 steel laminations and 4340 steel cores, which are heavily preloaded into the back iron/composite flywheel structures. Retainers axially restrain the radial bearing laminations.

Backup bearings are incorporated into the design in the event of magnetic bearing controller failure or excess bearing loads. These bearings consist of ceramic races with steel balls. The backup bearings are preloaded inside the axially outboard portions of the thrust end and non- thrust end bearing housings, so that they are not engaged (not rotating) during normal magnetic bearing operation. For the thrust end, this backup bearing assembly must carry an axial load. Therefore, an axial retainer is threaded into the thrust-end bearing housing.

\section{B. Structural Integrity: Composite Flywheel Ring Components}

Table 2 summarizes the three composite flywheel rings of the CHPS rotor (F1, F2, and F3) and the associated stress margins. Radial compressive, axial tensile and rz shear stresses (KSI) and hoop strain are shown for three temperatures $\left(75^{\circ} \mathrm{F}, 0^{\circ} \mathrm{F}\right.$, and $\left.225^{\circ} \mathrm{F}\right)$ with three rotating speed conditions ( $0,15,000$, and 20,000 rpm). Peak stresses or strains are highlighted. Design allowables are also presented in the lower part of the table. The hoop strain allowable was derived from hydroburst test data performed at an elevated temperature of $275^{\circ} \mathrm{F}$.

The table shows that the factor of safety values (calculated from the ratio of the design allowable divided by the induced stress or strain) are equal to or greater than 1.9, exceeding the goal of 1.5. Fatigue life ratings have not been determined, but general composite fatigue guidelines indicate that carbon reinforced epoxy laminates should possess "infinite" life if operated at or below $60 \%$ of the ultimate tensile strength, UTS, (fiber direction). The maximum hoop strain in the table is $0.61 \%$ and $60 \%$ of the UTS is $0.84 \%$, suggesting acceptable life.

Fatigue testing of composite rings using the same fiber/resin system, at elevated temperature, is ongoing at UT-CEM under related flywheel programs. Early results from these tests, at comparable strain excursions to 400,000 cycles and at $200^{\circ} \mathrm{F}$, indicate only about a $5 \%$ degradation in UTS. This suggests that the " $60 \%$ of UTS guideline" may be extremely conservative for this application.

\section{Structural Integrity: Metallic Rotor Components}

Table 3 summarizes all the metallic components of the CHPS rotor and the associated stress margins and fatigue analysis. Hoop and axial stresses (ksi) are shown for three temperatures $\left(75^{\circ} \mathrm{F}, 0^{\circ} \mathrm{F}\right.$, and $\left.225^{\circ} \mathrm{F}\right)$ with three rotating speed conditions (0, 15,000, and 20,000 rpm). Design allowables and fatigue data (S-N diagrams) for each of the metal alloys were extracted from MIL-HDBK $5 \mathrm{G}$. For the crack propagation analysis, $\mathrm{dA} / \mathrm{dN}$ data were obtained from the Navy report mentioned earlier and from cataloged information in the FLAGRO program.

Using stress excursions predicted using the CHPS rotor FEA model, each metallic rotor component was evaluated based on the defined duty cycle. The data in the table shows that the factor of safety values equal or are greater than CHPS program target of 1.5 (for material yield). With the exception of the radial bearing laminations (which have not yet been evaluated), all rotor components have greater than twelve lives of safe operation (minimum life rating was targeted to be 10). To complete the FLAGRO analysis for the radial bearing laminations, data for crack propagation in AISI 4130 will 
be needed. Tests will on the 4130 material will be required if the information cannot be found through additional literature searches.

\section{CONCLUSIONS}

Philosophy, approach, analysis, and design tools used to ensure that that CHPS machine rotor would have an adequate safe-life rating, based upon an anticipated duty cycle, which encompasses full combat operation as well as training, road marches, and peace time operations, were presented. Analysis results demonstrated that CHPS structural, safety, and life cycle requirements were met or exceeded for all components except the radial bearing laminations (which have not yet been analyzed).

\section{ACKNOWLEDGMENT}

The authors would like to thank John Kearney of Science Applications International, Inc., and Dominick Russo and Amos Alexander of CAES for their valuable technical contributions to this effort, and the Defense Advanced Research Projects Agency for funding support.

\section{REFERENCES}

[1] NASA Requirements for the International Space Station, SSP 30559 Rev B para. 3.5.7.

[2] Information compiled and provided courtesy of K. Konno, NASA Glenn Research Center.

[3] M.A. Spiegel, Theory and Problems of Statistics, Schaum's Outline Series, McGraw-Hill Publishing Co., New York, 1988, Chapter 11.

[4] K.G. Beauchamp and C.K. Yuen, Digital Methods for Signal Analysis, George Allen and Unwin LTD, London, 1979, pg 67-68.

[5] NASA/FLAGRO, version 2.0, rev. A, Fatigue Crack Growth Computer Program, NASA, 1994.

[6] T.J. McCaffrey, "Combined strength and toughness characterize new aircraft alloy," Advanced Materials and Processes, September 1992, p 47.

[7] E.U. Lee, "Fatigue crack growth in AerMet ${ }^{\circledR} 100$ steel," Naval Air Development Center, Report No. NADC-91111-60, October 1991.

\section{TABLES AND FIgURES}

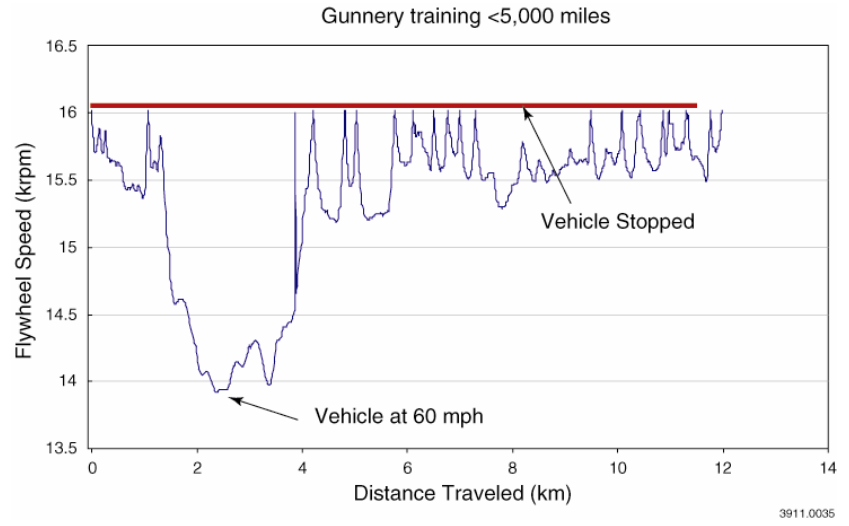

Fig. 1. Flywheel cycling requirements for mobility load leveling with EM armor and ETC discharges always enabled. 
TABLE 1. REPRESENTATIVE PROBABILITIES FOR SUCCESS FOR VARIOUS CRITICAL AEROSPACE APPLICATIONS.

\begin{tabular}{|c|c|}
\hline Application & $\begin{array}{l}\text { Reliability require- } \\
\text { ment on component } \\
\text { safelife design }\end{array}$ \\
\hline \multicolumn{2}{|l|}{ U.S. Army (1992) } \\
\hline $\begin{array}{l}\text { - Helicopter safelife components } \\
\text { fatigue design }\end{array}$ & $0.999999\left(0.9_{6}\right)$ \\
\hline $\begin{array}{l}\text { - Airbus aircraft (system reliability } \\
\text { against catastrophic failures) }\end{array}$ & $0.9_{6}$ (per light year) \\
\hline $\begin{array}{l}\text { - Airplane landing gear (system } \\
\text { reliability against fatal accident) }\end{array}$ & $0.9_{6}$ \\
\hline \multicolumn{2}{|l|}{ Boeing Defense and Space Group } \\
\hline \multicolumn{2}{|l|}{ Helicopter Division (1991) } \\
\hline \multicolumn{2}{|l|}{ U.S. Army (1998) } \\
\hline $\begin{array}{l}\text { - Light Experimental Helicopter } \\
\text { Program }\end{array}$ & $0.9_{6}$ \\
\hline $\begin{array}{l}\text { - Oil rig platform (reliability against a } \\
\text { class III serious failure) }\end{array}$ & $0.9_{6}$ (per light year) \\
\hline $\begin{array}{l}\text { - Automotive transmission components } \\
\text { (typical, over warranty life) }\end{array}$ & $0.9_{6}$ \\
\hline
\end{tabular}

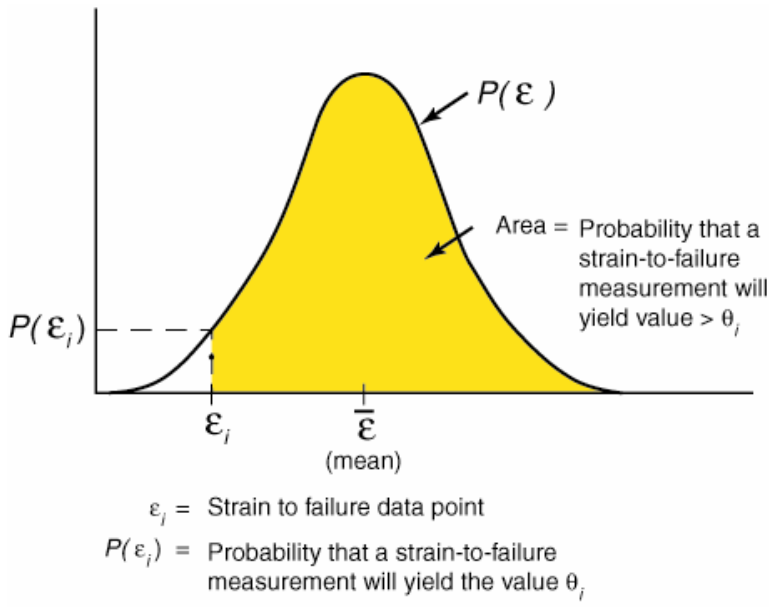

3911.0037

Fig. 2. Probability distribution for strain-to-failure measurements (nonnormalized), showing the mean strain-to-failure and a strain-to-failure data point that could serve as a rotor maximum strain operating point.

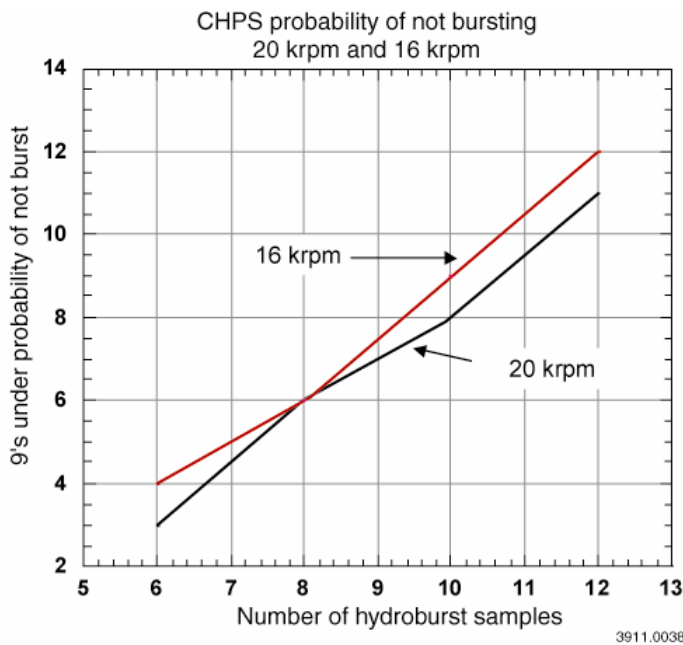

Fig. 3. Strain-to-failure probability of not bursting vs. number of samples.

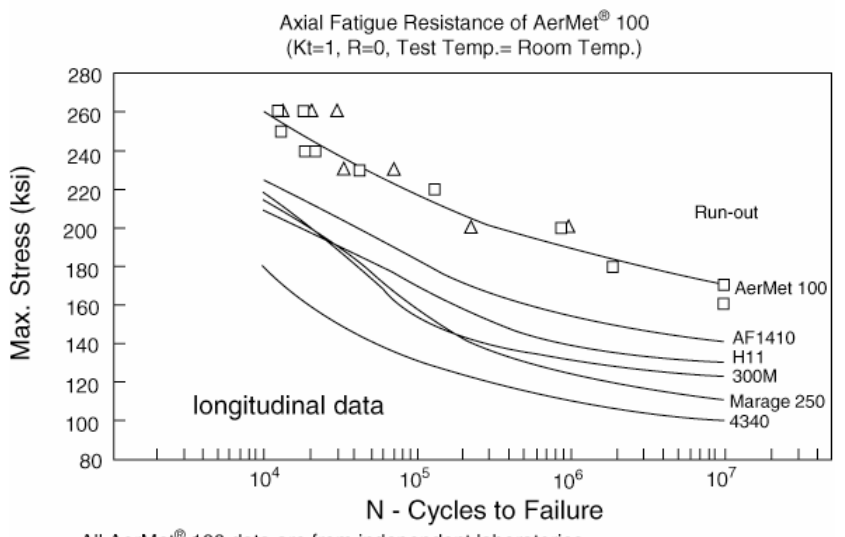

All AerMet ${ }^{\otimes} 100$ data are from independent laboratories

AerMet ${ }^{\circledR} 100$ data are for both 875 and $900^{\circ} \mathrm{F}$ aging treatments (different labs) Other data are from Mil-Handbook 5D or Aerospae Structural Metals Handbook

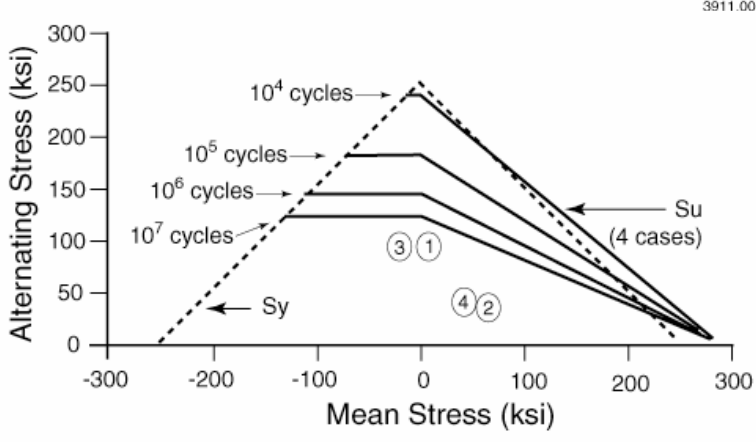

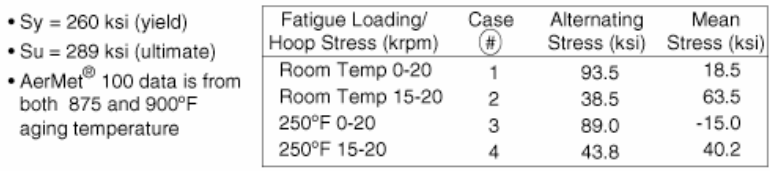

S-N axial fatigue resistance plot provided by Carpenter, Inc.

Fig. 4. AerMet ${ }^{\circledR} 100$ analysis for fatigue resistance.

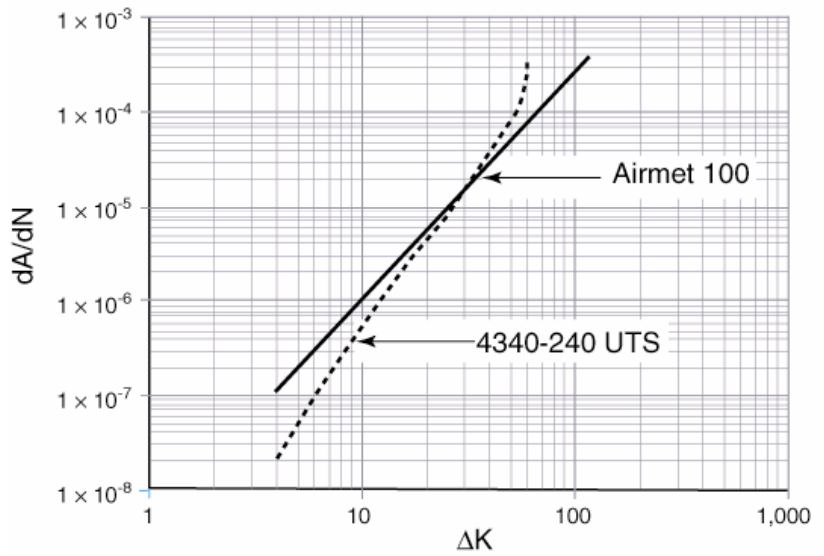

AerMet ${ }^{\circledast} 100$ exhibits a high tolerance to fatigue in laboratory controlled, polished specimens; however, notch sensitivity data indicates a high rate of crack propagation. Power law for AirMet ${ }^{\otimes} 100: y=3.745^{-09} \times 2.438: R^{2}=1$

Fig. 5. Crack growth propagation rates, AerMet ${ }^{\circledR} 100$ and AISI 4340. 


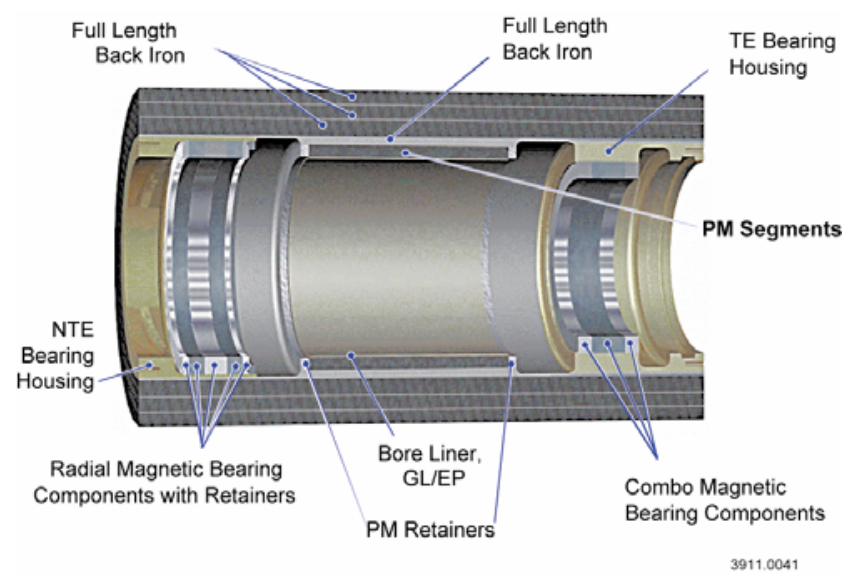

Fig. 6. CHPS rotor cross-section.

TABLE 2. ANALYSIS RESULTS, FLYWHEEL RING COMPONENTS.

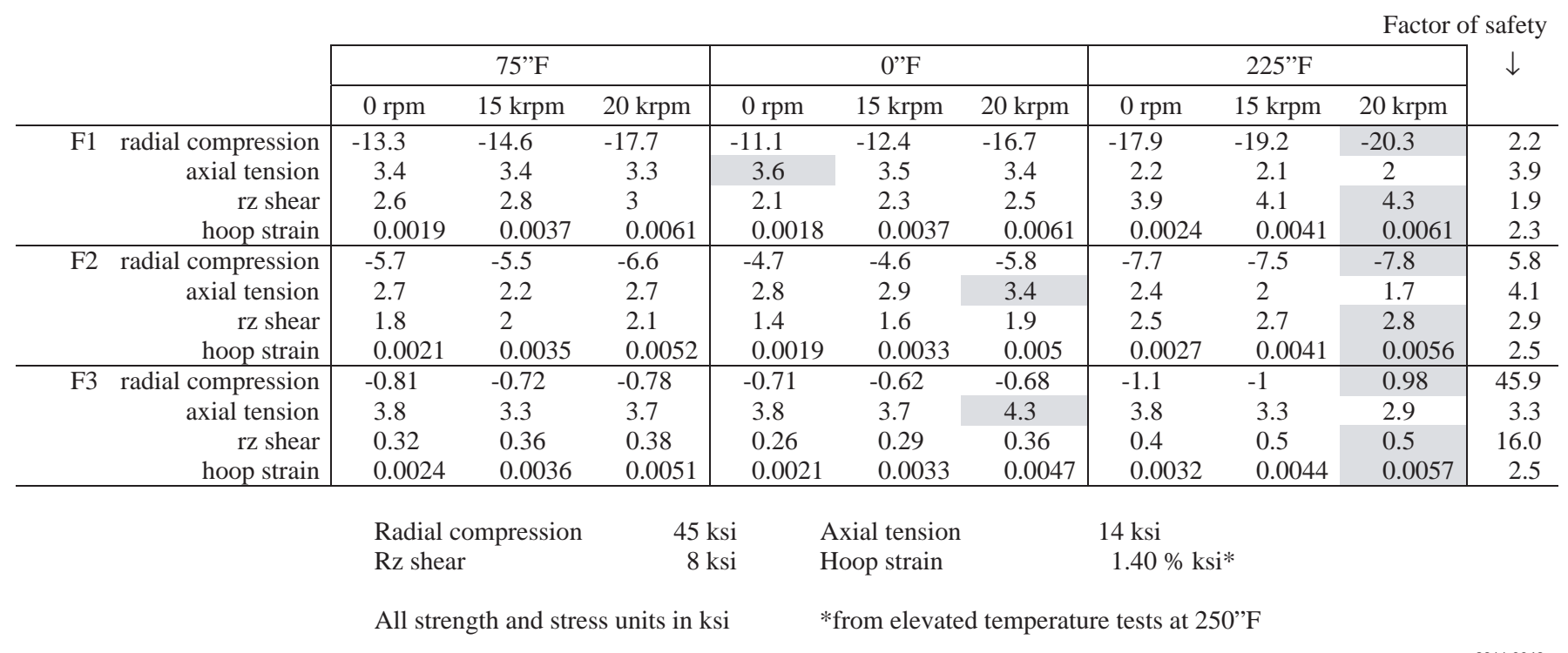


TABLE 3. ANALYSIS RESULTS, METALLIC ROTOR COMPONENTS.

\begin{tabular}{|c|c|c|c|c|c|c|c|c|c|c|c|c|c|c|c|c|c|}
\hline & \multicolumn{16}{|c|}{ number of duty cycles } \\
\hline & & \multicolumn{5}{|c|}{ Room temperature } & \multicolumn{5}{|c|}{$0 ” \mathrm{~F}$} & \multicolumn{5}{|c|}{$225 ” F$} & \multirow[b]{2}{*}{$\downarrow$} \\
\hline & & $\begin{array}{c}0 \\
\mathrm{rpm}\end{array}$ & $\begin{array}{c}15 \\
\text { krpm }\end{array}$ & $\begin{array}{c}20 \\
\text { krpm }\end{array}$ & mean & range & $\begin{array}{c}0 \\
\mathrm{rpm}\end{array}$ & $\begin{array}{c}15 \\
\text { krpm }\end{array}$ & $\begin{array}{c}20 \\
\text { krpm }\end{array}$ & mean & range & $\begin{array}{c}0 \\
\mathrm{rpm}\end{array}$ & $\begin{array}{c}15 \\
\text { krpm }\end{array}$ & $\begin{array}{c}20 \\
\mathrm{krpm}\end{array}$ & mean & range & \\
\hline \multirow[t]{2}{*}{ Backiron (4340) } & Hoop stress & -85.3 & 16 & 95.1 & 4.9 & 180.4 & -72.1 & 29.1 & 108 & 17.95 & 180.1 & -105 & -10.1 & 69.2 & -17.9 & 174.2 & \multirow[t]{2}{*}{$>12$} \\
\hline & Axial & 45.8 & 52.5 & 57.6 & 51.7 & 11.8 & 23 & 28.4 & 33.6 & 28.3 & 10.6 & 86.3 & 93 & 98 & 92.15 & 11.7 & \\
\hline \multirow{2}{*}{$\begin{array}{r}\text { Radial bearing } \\
\text { housing (titanium) }\end{array}$} & Hoop stress & -19.7 & 12.8 & 37.8 & 9.05 & 57.5 & -17 & 15.1 & 41.7 & 12.35 & 58.7 & -23.8 & 8.4 & 33.5 & 4.85 & 57.3 & \multirow[t]{2}{*}{$>20$} \\
\hline & Axial & & & & 0 & 0 & & & & 0 & 0 & & & & 0 & 0 & \\
\hline $\begin{array}{r}\text { Radial bearing } \\
\text { lams (4130) }\end{array}$ & Hoop stress, id & -50.5 & 32.6 & 97.1 & 23.3 & 147.6 & -41.8 & 41.3 & 106 & 32.1 & 147.8 & -67.9 & 15.2 & 79.9 & 6 & 147.8 & * \\
\hline $\begin{array}{r}\text { Radial bearing } \\
\text { ends (4340) }\end{array}$ & $\begin{array}{r}\text { Hoop stress } \\
\text { Axial }\end{array}$ & -50.5 & 32.6 & 97.1 & $\begin{array}{c}23.3 \\
0\end{array}$ & $\begin{array}{c}149.6 \\
0\end{array}$ & -41.8 & 41.3 & 106 & $\begin{array}{c}32.1 \\
0\end{array}$ & $\begin{array}{c}147.8 \\
0\end{array}$ & -67.9 & 15.2 & 79.9 & $\begin{array}{l}6 \\
0\end{array}$ & $\begin{array}{c}147.8 \\
0\end{array}$ & $>15$ \\
\hline $\begin{array}{r}\text { Radial bearing } \\
\text { spacer (4340) }\end{array}$ & Hoop stress, id & -51.6 & 31.8 & 96.6 & 22.5 & 148.2 & -42.6 & 40.8 & 106 & 31.7 & 148.6 & -69.8 & 13.6 & 78.4 & 4.3 & 148.2 & $>15$ \\
\hline $\begin{array}{r}\text { Combo bearing } \\
\text { housing (titanium) }\end{array}$ & $\begin{array}{r}\text { Hoop stress, id } \\
\text { Axial }\end{array}$ & -32.1 & 14.6 & 50.9 & $\begin{array}{l}9.4 \\
0\end{array}$ & $\begin{array}{r}83 \\
0\end{array}$ & -24.6 & 22.2 & 58.5 & $\begin{array}{c}16.95 \\
0\end{array}$ & $\begin{array}{c}83.1 \\
0\end{array}$ & -47.8 & -1 & 35.2 & $\begin{array}{c}-6.3 \\
0\end{array}$ & $\begin{array}{r}83 \\
0\end{array}$ & $>20$ \\
\hline $\begin{array}{r}\text { Combo bearing } \\
\text { lams (4130) }\end{array}$ & Hoop stress, id & -53.3 & 25.4 & 86.5 & 16.6 & 139.8 & -42.6 & 36 & 97 & 27.2 & 139.6 & -75 & 3.7 & 64.8 & -5.1 & 139.8 & * \\
\hline $\begin{array}{r}\text { Combo bearing } \\
\text { ends (4340) }\end{array}$ & Hoop stress & -53.5 & 25.1 & 86.1 & 16.3 & 139.6 & -42.8 & 35.7 & 96.7 & 26.95 & 139.5 & -74.9 & 3.7 & 64.8 & -5.05 & 139.7 & $>20$ \\
\hline $\begin{array}{r}\text { Combo end mag } \\
\text { retainer (4340) }\end{array}$ & Hoop stress & -53.8 & -5.1 & 32.8 & -10.5 & 86.6 & -45 & 34.6 & 41.6 & -1.85 & 86.3 & -71.2 & -22.2 & 15.8 & -27.7 & 87 & $>20$ \\
\hline
\end{tabular}

